\title{
Refractive errors
}

\author{
Epidemiology, Effects and Treatment Options
}

Ulrich Schiefer, Christina Kraus, Peter Baumbach, Judith Ungewiß, Ralf Michels

\section{SUMMARY}

Background: All over the world, refractive errors are among the most frequently occuring treatable disturbances of visual function. Ametropias have a prevalence of nearly $70 \%$ among adults in Germany and are thus of great epidemiologic and socio-economic relevance.

Methods: In the light of their own clinical experience, the authors review pertinent articles retrieved by a selective literature search employing the terms "ametropia, "anisometropia," "refraction," "visual acuity," and "epidemiology."

Results: In 2011, only $31 \%$ of persons over age 16 in Germany did not use any kind of visual aid; $63.4 \%$ wore eyeglasses and $5.3 \%$ wore contact lenses. Refractive errors were the most common reason for consulting an ophthalmologist, accounting for $21.1 \%$ of all outpatient visits. A pinhole aperture (stenopeic slit) is a suitable instrument for the basic diagnostic evaluation of impaired visual function due to optical factors. Spherical refractive errors (myopia and hyperopia), cylindrical refractive errors (astigmatism), unequal refractive errors in the two eyes (anisometropia), and the typical optical disturbance of old age (presbyopia) cause specific functional limitations and can be detected by a physician who does not need to be an ophthalmologist.

Conclusion: Simple functional tests can be used in everyday clinical practice to determine quickly, easily, and safely whether the patient is suffering from a benign and easily correctable type of visual impairment, or whether there are other, more serious underlying causes.

\section{Cite this as}

Schiefer U, Kraus C, Baumbach P, Ungewiß J, Michels R: Refractive errors-epidemiology, effects and treatment options. Dtsch Arztebl Int 2016; 113: 693-702.

DOI: 10.3238/arztebl.2016.0693

Aalen University of Applied Sciences, Competence Center Vision Research, Study Program Ophthalmic Optics: Prof. Schiefer, Ms Kraus, B.Sc., Prof. Dr. rer. nat. Baumbach, Ms Ungewiß, M.Sc., Dipl.-Ing. (FH) Michels

Department of Ophthalmology, Tübingen University Hospital, Tübingen: Prof. Schiefer
M ost of our information about the world around us comes from our visual system (1). For this system to function well, relevant objects in our field of vision have to be imaged in focus on the retina. Refractive errors are among the most frequently occurring treatable "diseases." The meta-analysis published by Huang et al. (2) describes the rapidly increasing prevalence of myopia worldwide, particularly in Asia.

In Germany too, with a prevalence of nearly $70 \%$ in the adult population, refractive errors are of major epidemiological and socio-economic relevance. In 2011 , only around $31 \%$ of persons over the age of 16 years used no visual aids: 63 . 4\% had glasses and 5.3\% wore contact lenses $(3,4)$. Refraction problems were the most frequent reason for visiting an ophthalmologist $(21.1 \%)$ - followed by glaucoma (19.3\%), lens pathology/cataract $(14.9 \%)$, and diseases of the posterior compartment of the eye (12.5\%) (5). In 2010 the average German citizen spent $€ 55.42$ on the services of opticians, $€ 32.02$ on care by ophthalmologists, and a further $€ 6.16$ on eye medications (5).

\section{Learning goals}

The aim of this article is to

- describe the characteristic symptoms of refractive errors,

- present simple diagnostic aids for use in the reader's own practice, and

- impart a basic understanding of optical care.

Owing to the limited scope of this article, topics such as contact lenses, intraocular lenses, and further surgical correction of refractive errors are mentioned only in passing.

\section{Diagnosis}

The simple stenopeic slit (pinhole aperture) represents the diagnostic key to practically all forms of refraction-

\section{Epidemiology}

Poor vision is one of the most frequently occurring functional impairments worldwide: in Germany almost $70 \%$ of persons over 16 need glasses or contact lenses. 


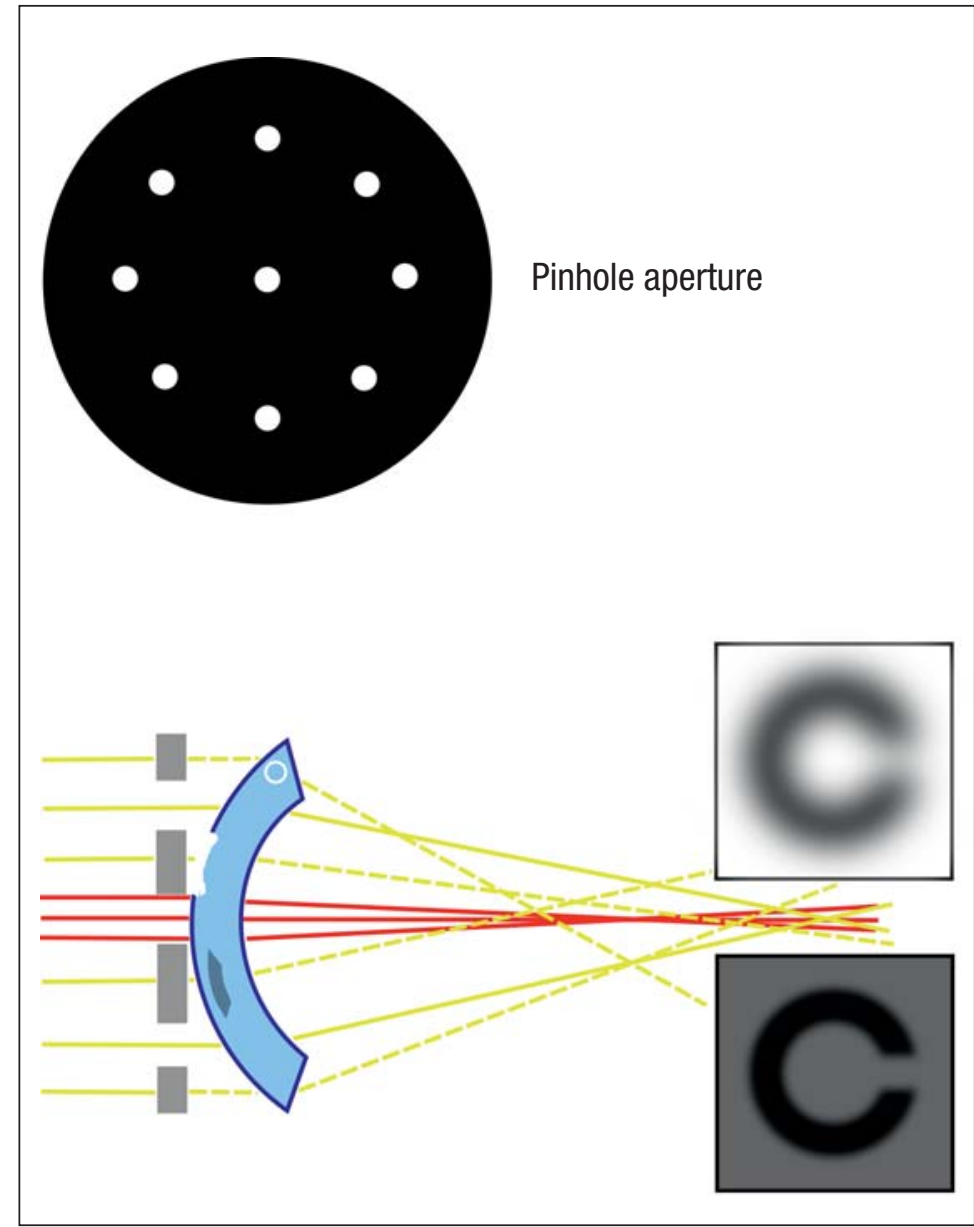

Figure 1: Pinhole aperture - principle and diagnostic relevance: 0pacities or irregularities in the refractive media interfere (green lines) with the ideal image-forming process (solid green lines).

Holding a pinhole aperture in front of the eye distinctly improves the image quality and thus the detection of the initially barely perceptible gap in the Landolt C (upper $\mathrm{C}$ on white background) by largely eliminating the "distracting" rays (dashed green lines), so that only axial and paraxial rays (red lines) reach the eye. However, masking out parts of the image reduces the retinal illumination - the visual impression is generally darker (lower $\mathrm{C}$ on dark background). with writing on it or an open book) through the pinhole. If the patient's visual acuity is greatly improved, ametropia (myopia, hyperopia, astigmatism) or early impairment of the refractive media is highly likely. The shortsighted, in particular, tend to improve their distance vision by screwing up their eyes so only a narrow slit remains open.

Tip

Often patients say they see "nothing" or "only darkness." In this case it may be helpful to advise them to look for the "keyhole" (i.e. the pinhole aperture). Alternatively several holes can be made close to each other, e.g., with a fork - the patient will then almost certainly find one of the holes in such a "sieve". By the way, the pinhole glasses offered on the internet work on the same principle.

A pinhole aperture works by masking the marginal rays that would otherwise-particularly in the presence of opaque media or (irregular) refractive defects-hinder formation of a focused image on the retina (Figure 1).

If the pinholes of a stenopeic aperture are too small they cause diffraction phenomena, further worsening image perception.

Natives of the Arctic took advantage of the stenopeic principle long ago, sawing stenopeic slits in whale bones. These visual aids served primarily not to increase visual acuity but to reduce the ambient luminance level in a glaring glacial landscape (serving the same function as sunglasses). This secondary effect of a pinhole aperture should be borne in mind when working towards a diagnosis: a pinhole aperture also improves the patient's visual impression in the presence of cone dystrophy or other degenerative or dystrophic diseases of the retina or macula. In cone dystrophy the inhibitory action of this receptor system on the rods is absent, so the latter (also) function under photopic conditions, leading to "retinal glare". By reducing the amount of light reaching the retina, a pinhole thus has the same positive effect as a neutral density gray filter.

If looking through a pinhole does not noticeably improve central visual acuity, further investigations are required to rule out lesions of the visual pathway(s) - e.g., the swinging flashlight test and investigation of the visual field and the examination of the anterior and posterior compartments of the eye by means of slit-lamp examination and ophthalmoscopy (6).

\section{Diagnosis}

A pronounced increase in visual acuity when a pinhole aperture is held in front of the eye clearly indicates a problem with refraction.

\section{Darker visual impression}

Masking by the pinhole aperture reduces the intensity of light reaching the retina-the visual impression becomes darker. 


\section{Preliminary assessment of visual acuity Distance vision}

The visual acuity provides information about the resolving power of the eye. To minimize the influence of distance, acuity is measured using not object size (e.g., in centimeters) but rather the visual angle (e.g., in minutes of arc). Visual acuity is inversely proportional to the visual angle: If an object is recognized correctly at an angle of 1 minute (1'), the visual acuity is $1.0(20 / 20)$. If it is still recognized at an angle of $0.5^{\prime}$, the acuity is 2.0 (40/20). Conversely, if an angle of $2 '$ is needed for correct recognition, the visual acuity is $0.5(10 / 20)$. Young persons can definitely achieve a (distance) visual acuity of 2.0 .

As stipulated by DIN 58220 (7) and ISO 10938 (8), the so-called Landolt C, a ring with a gap at one of eight equally spaced positions, is the only system of optotypes that is internationally accepted for certification of eyesight (eFigure 1). At least $60 \%$ of a line of at least five identically sized Landolt Cs with gaps in different positions must be read correctly for the corresponding level of visual acuity to be assigned.

A computer-based eyesight test using Landolt C optotypes can be downloaded from the internet (9). For measurement of very poor visual acuity, charts with large Landolt Cs can be printed in one's own office (10). In principle, visual acuity can also be assessed using other optotypes, e.g., numerals or letters. In that case the optotype selection should ensure equal recognizability for all characters for one level of vision are equally recognizable (among the numerals, for instance, an 8 is much harder to recognize than a 4). In the English-speaking countries the ETDRS (Early Treatment of Diabetic Retinopathy Study) charts are widely used. These charts are now also being employed in the German-speaking region, e.g., in studies.

Standardized tests such as these will often not be available in a non-ophthalmological office or outpatient facility. As a rough measure, one can then resort to testing the distance at which objects can be recognized. The characters on German automobile license plates, for example, are written with lines approximately $13 \mathrm{~mm}$ wide. In daylight under good visual conditions, a person with a visual acuity of 1.0 (resolving power 1') has to be able to read more than half $(60 \%)$ of the characters correctly at a distance of ca. $45 \mathrm{~m}$. The Table shows the recognition distances for other levels of visual acuity.

\section{Cone dystrophy}

A pinhole aperture also improves the visual impression in patients with cone dystrophy and other degenerative or dystrophic diseases of the retina and macula.

\section{TABLE}

Reading distances (in meters) for German automobile license plates as a rough indication of central visual acuity*

\begin{tabular}{c|c|c|}
\hline Acuity & Recognition distance $(\mathrm{m})^{* 2}$ & Remarks \\
\hline 2.0 & 90 & \\
\hline 1.0 & 45 & $\begin{array}{c}\text { Minimum visual acuity (in the better eye) } \\
\text { for fitness to drive }\end{array}$ \\
\hline 0.5 & 22.5 & \\
\hline 0.2 & 9 & \\
\hline 0.1 & 4.5 & \\
\hline
\end{tabular}

${ }^{* 1}$ In daylight and good visibility, more than half $(60 \%)$ of the round letters or numerals must be recognized correctly.

${ }^{* 2}$ Rounded

\section{Near vision}

Determination of single-optotype visual acuity (usually by means of pocket optotype cards) for assessment of near vision is generally of less importance, performed only if no distance vision test is available. The principal consideration in near vision is reading, in which not only single characters but whole groups of letters are taken in at once and have to be connected by means of saccades $(11,12)$. Preliminary assessment of vision is achieved by testing the (fluent) reading of standard newspaper type at a distance of $40 \mathrm{~cm}$ in good lighting; this corresponds to (near) visual acuity of ca. 0.5 . Central visual field defects or distortions of image perception (metamorphopsia) may severely impair reading ability. Metamorphopsia, in particular, can be evaluated with the aid of an Amsler Grid (in the absence of which one can also use a sheet of quad paper with a central fixation point). In this test the patient-with adequate correction of near vision if appropriate - is asked to focus on the fixation point of an evenly lit Amsler Grid presented at the stipulated distance (usually 40 $\mathrm{cm})$ with the fellow eye covered. In most cases metamorphopsia manifests as localized "waviness" of the lines, often accompanied by an altered perception of "brightness" in the same area. In the context of documentation of results or follow-up, patients can mark the location of these distortions on the grid themselves (while continuing to focus on the fixation point).

\section{Visual acuity}

Vision of $1.0(20 / 20)$ corresponds to correct identification of more than half of the (round) characters on a German automobile license plate at a distance of $45 \mathrm{~m}$ in good light. 


\section{Ametropia}

Ametropia is the most frequent reason for reduction in visual acuity. Ametropia is determined either using dedicated devices (largely without the active participation of the person involved; objective refraction) or by means of asking broadly standardized questions while corrective lenses are held in front of the eye (subjective refraction). Detailed descriptions of refraction techniques can be found in the relevant literature (13-19). The reproducibility of the latter procedure is limited, even under optimal conditions, by the wide variation of the probands' responses (20). Inadequate compensation of refraction can lead to uni- or bilateral reduction of visual acuity and also to significant impairments of visual comfort; these include, among others, the so-called asthenopic symptoms (e.g., the feeling that the eye is dry, sensation of a foreign body, ocular reddening, double vision, rapid fatigue, reluctance to read, headache).

\section{Spherical ametropia}

The simplest underlying refractive error is the so-called spherical ametropia with a rotationally symmetrical discrepancy between the length of the eyeball and the eye's refractive power; this can be corrected by simple plus or minus lenses. In a large majority of cases the overall length deviates from the ideal of ca. $24 \mathrm{~mm}$ (longitudinal ametropia). Excessive length induces myopia (shortsightedness) and reduced length results in hyperopia (farsightedness). Less commonly, the refractive power of the optical components diverges from the norm (e.g., altered radii of curvature of the cornea and/or lens, or increased refractive index of the lens caused by uncontrolled diabetes mellitus).

The refractive power ("strength") of a corrective lens is measured in diopters $(\mathrm{dpt})$; this value is the inverse of the focal distance in meters. As a rule of thumb, each millimeter of deviation from the ideal length of the eye results in ametropia of ca. $3 \mathrm{dpt}$.

\section{Myopia}

In shortsightedness, also known as myopia, distant objects are not seen in focus. The reason is that the refractive power of the visual system is too high in relation to the length of the eyeball. As shown in eFigure $2 b$, the focused image of a distant object forms in front of the retina and the image is thus blurred at the fovea. In contrast, objects close to the observer are imaged in focus on the retina with no need for accommodation.
The smaller the distance of focus without accommodation, the stronger the myopia. For example, a shortsighted person with a deficit in refractive power of $-2 \mathrm{dpt}$ sees in focus with no or only slight accommodation at a distance of $50 \mathrm{~cm}$. Approximately $35 \%$ of the German population between the ages of 35 and 74 years is affected by myopia with ametropia of more than $-0.5 \mathrm{dpt}$ (21).

The best-known options for correction of myopia are diverging lenses and contact lenses (eFigure $2 b$ ). These meniscus-shaped optic lenses have a negative effect; they displace the focus of the image posteriorly from the vitreous body to the retina, resulting in clear image perception.

For lenses with a negative dioptric effect (minus lenses), the greater the distance between the corrective lens and the principal plane (this lies ca. $1.5 \mathrm{~mm}$ behind the cornea), the more pronounced the miniaturizing effect of the lens. Moving the glasses forwards or backwards (i.e., increasing the so-called vertex distance) displaces their focal point in the same direction. Shortsighted people use this phenomenon to compensate for inadequate correction by their glasses. Someone with overcorrection (minus lenses too strong $=$ focal point behind the retina) will push his or her glasses forwards towards the tip of the nose. Conversely, a person with undercorrection (minus lenses too weak $=$ focal point in front of the retina) will move their glasses backwards towards the the root of the nose to improve focus.

Minus glasses have a miniaturizing effect that is noticed both by the wearers and by those looking at them. An eye behind a minus lens appears smaller-most prominently, the temporal margin of the orbit seems to be shifted medially (eFigure $3 b$ ). eFigure $3 a-c$ gives an impression of the extent of orbital margin distortion depending on the strength of the corrective glasses.

Another option for the correction of myopia is refractive surgery. "Flattening" of the cornea by means of laser treatment has the effect of increasing the radius of curvature of the corneal surface. This central removal of material also alters the biomechanical characteristics of the cornea, potentially affecting among other things the applanatory measurement of internal ocular pressure in the course of investigation of glaucoma (22-24). Kerato-refractive procedures are not discussed in more detail here owing to the limited scope of this article, but the relevant literature is cited in review articles $(25,26)$.

\section{Insufficient refractive compensation}

Faulty refractive compensation may lead not only to uni- or bilateral reduction in visual acuity, but also to considerable loss of visual comfort.

\section{Spherical ametropia}

In spherical ametropia, rotational asymmetry leads to discrepancy between the length of the eyeball and the eye's refractive power; this can be corrected by simple plus or minus lenses. 

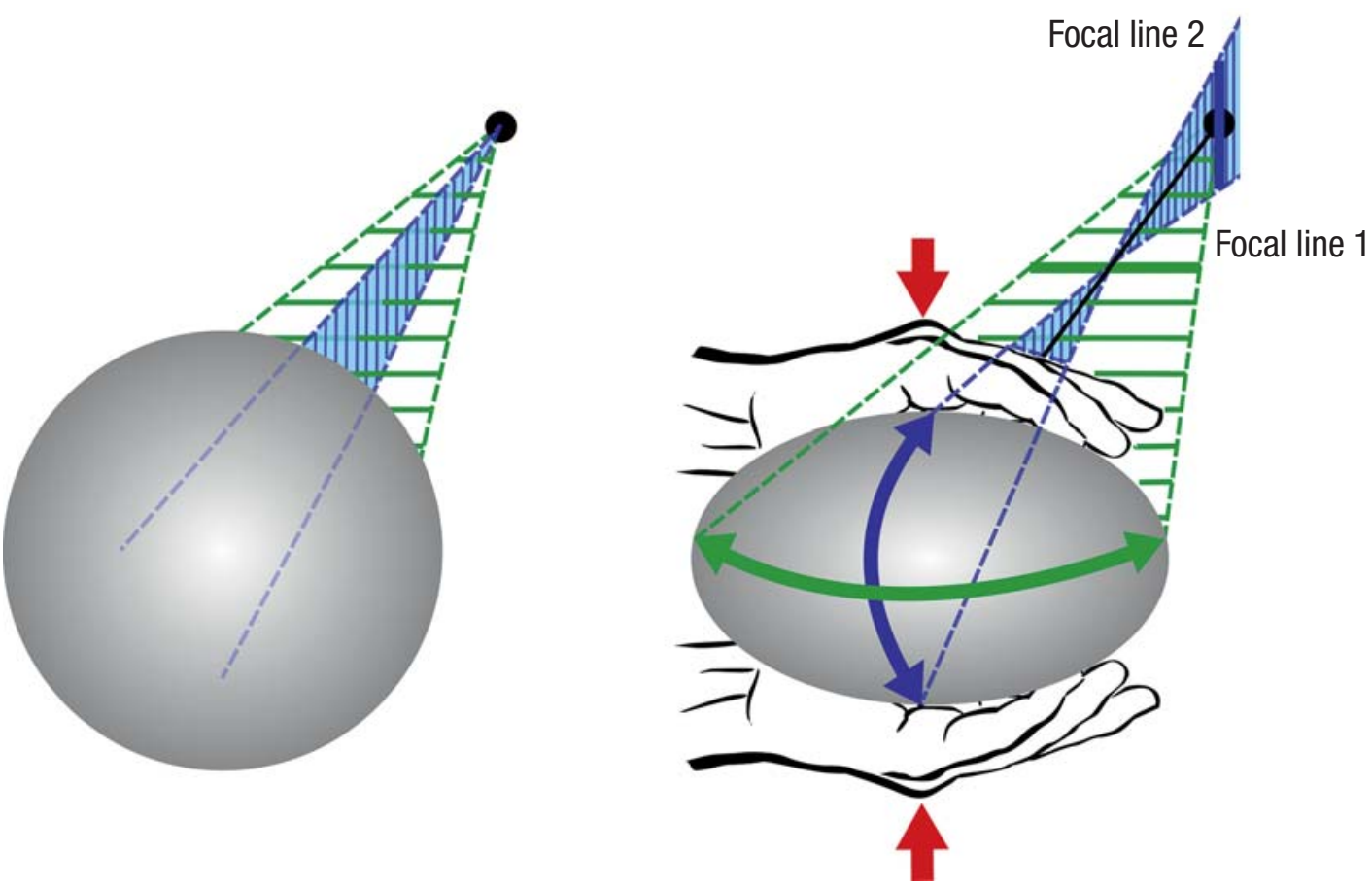

Figure 2: Pathogenesis of astigmatism in the form of non-rotationally symmetrical deformation of the refractive media.

Left: Formation of a spherical image with rotationally symmetrical refractive media;

Right: Schematic depiction of the pathogenesis of astigmatism in the form of non-rotationally symmetrical deformation of the refractive media. Instead of being spherical, the lens now forms an ellipsoid resembling a football, with two different radii of curvature. Instead of one focal point as on the left, there are now two focal lines. The more anterior horizontal focal line 1 corresponds with the vertical meridian (blue bow-shaped line) with a smaller radius of curvature and thus a principal plane with higher refractive power, while focal line 2 corresponds to the horizontal meridina (green bow-shaped line) with a larger radius of curvature and a principal plane with lower refractive power. This constellation is called "with-the-rule" astigmatism" (see also Figure 3, Supplementary Material and eFigure 5).

\section{Hyperopia}

In hyperopia, also known as farsightedness, a relaxed gaze into the distance (without accommodation) results in a blurred image. The reason is that the refractive power of the visual system is too small in relation to the length of the eye: the focused image of a distant object lies behind the retina and the image on the retina is thus unclear (eFigure 2c). Young persons can compensate for this error "automatically"/involuntarily by reducing the radius of curvature (accommodation) and thus changing the refractive power of the ocular lens. The image is displaced anteriorly onto the retina and the visual impression becomes focused. Clear vision is therefore possible for a young person with farsightedness, but at the cost of increased accommodation (latent hyperopia). If the object being viewed is close to the observer, the degree of accommodation required to bring it into focus is much greater, increasing the risk of asthenopic symptoms (comparatively unspecific symptoms such as pain in the eye, ocular reddening, dry eye, and sometimes double vision, transient blurred vision, or headache). These symptoms occur particularly in the evening, in poor lighting, and after a long period of concentration on close objects. In Germany, $31.8 \%$ of the population between the ages of 35 and 74 years is affected by hyperopia of more than $+0.5 \mathrm{dpt}(21)$.

The most widespread option for correction of hyperopia is prescription of converging lenses or contact

\section{Correction with lenses}

In myopia, optic lenses displace the focus of the image posteriorly from the vitreous body to the retina, resulting in clear image perception.

\section{Hyperopia}

With a relaxed gaze (without accommodation), the focus of a distant object lies behind the retina and the image on the retina is thus unclear. 
lenses (eFigure 2c). These meniscus-shaped optical lenses have a positive effect, displacing the focus of images of distant objects from their original position behind the eye to the retina, producing a clear picture. Converging lenses enlarge the image perceived by the person using them. At the same time, the hyperopic eye behind the glasses appears larger-the temporal margin of the orbit seems to be displaced laterally (eFigure 3c).

In principle, kerato-refractive surgery can also be applied to the correction of hyperopia: laser treatment is used to "steepen" the curvature of the corneal surface, thus decreasing the radius of curvature.

\section{(Regular) cylindrical ametropia}

Cylindrical ametropia arises whenever the cause of ametropia lies in a non-rotationally symmetrical deformation of the refractive media. The situation is comparable to that of an initially spherical ball that is pressed between the hands and thus flattened. In the plane (principal plane) perpendicular to the hand surfaces exerting the pressure, the ball is compressed into a rotation ellipsoid (resembling a football), the radius of curvature is therefore reduced, and the refractive power increases (Figure 2). In the other principal plane, perpendicular to the first, the radius of curvature is greater and the refractive power thus lower. In cylindrical ametropia, therefore, the refractive power is different in different meridians (directions) and thus results in a line-shaped distorted image of the original punctiform object. Rather than a focal point, the person affected may perceive a focal line. The cause is usually deformation of the cornea (external astigmatism). The much less common internal astigmatism (deformation of the ocular lens) is harder to quantify.

In Germany, $32.3 \%$ of the population between the ages of 35 and 74 years is affected by significant astigmatism greater than $0.5 \mathrm{dpt}$ (21).

In the great majority of cases, the principal planes are perpendicular to one another. The astigmatism is then termed regular and can be compensated using socalled cylindrical lenses of suitable axis and refractive power. If the principal planes are not perpendicular, the rarer irregular astigmatism is present. Irregular astigmatism cannot be fully corrected with (spherocylindrical) lenses, but the effects of these lenses can usually be noticeably improved by holding a pinhole aperture in front of them. If the root cause of the problem is surface irregularity of the cornea with im- pairment of the tear film, a rigid gas-permeable contact lens may bring improvement.

Most cases of regular astigmatism are compensated by means of cylindrical lenses. These are not rotationally symmetrical, but segments of a glass cylinder (eFigure 4a). While the principal plane lying parallel to the axis of the cylinder has no optical effect, a cylindrical lens exerts its maximum effect perpendicular to the axis.

The goal of determining refraction in cylindrical astigmatism is to provide the astigmatic eye with a corrective cylindrical lens that has an identical alignment of the axis and the absolute dioptric value but opposite algebraic symbol (plus instead of minus, or vice versa). This combination produces a "plane-parallel plate" and the astigmatism is compensated (eFigure 4b).

\section{Classification of astigmatism by axis alignment}

Classification of astigmatism according to the alignment of the axis is not only of academic interest but by all means also has functional or prognostic importance; this is illustrated in the eSupplement (eFigure 5a-d).

The axis position of the corrective (minus) cylindrical lens is a criterion for classification of astigmatism. As laid down in the TABO guidelines, originally formulated by the Technischer Ausschuss für Brillenoptik (Technical Committee for Spectacle Optics) in 1928, the alignment of the axis is described from the viewpoint of the examiner (face to face). The $0^{\circ}$ position corresponds to the horizontal axis/orientation of the minus or plus cylinder (Figure 3). For both eyes the angle increases when the cylinder axis turns in the mathematically positive direction (i.e., counterclockwise) and ends at $180^{\circ}$.

The frequency distribution of axis alignment of the corrective minus cylinder in a large population is shown in Figure 3. With-the-rule astigmatism occurs most often, followed by against-the-rule astigmatism; oblique astigmatism is much rarer (21). Particularly in monocular/unilateral cases with pronounced deformation, oblique astigmatism is associated with a high risk of amblyopia $(27,28)$.

\section{Presbyopia}

In age-related farsightedness, or presbyopia, the eye is restricted in its ability to focus on close objects. The underlying causes are loss of elasticity of the ocular lens and structural changes in the area of the zonular

\section{Glasses}

Glasses with positive refractive power correct hyperopic errors of refraction (farsightedness). Around $32 \%$ of German adults have hyperopia exceeding $+0.5 \mathrm{dpt}$.

\section{Cylindrical ametropia}

Cylindrical ametropia arises from a nonrotationally symmetrical deformation of the refractive media. 


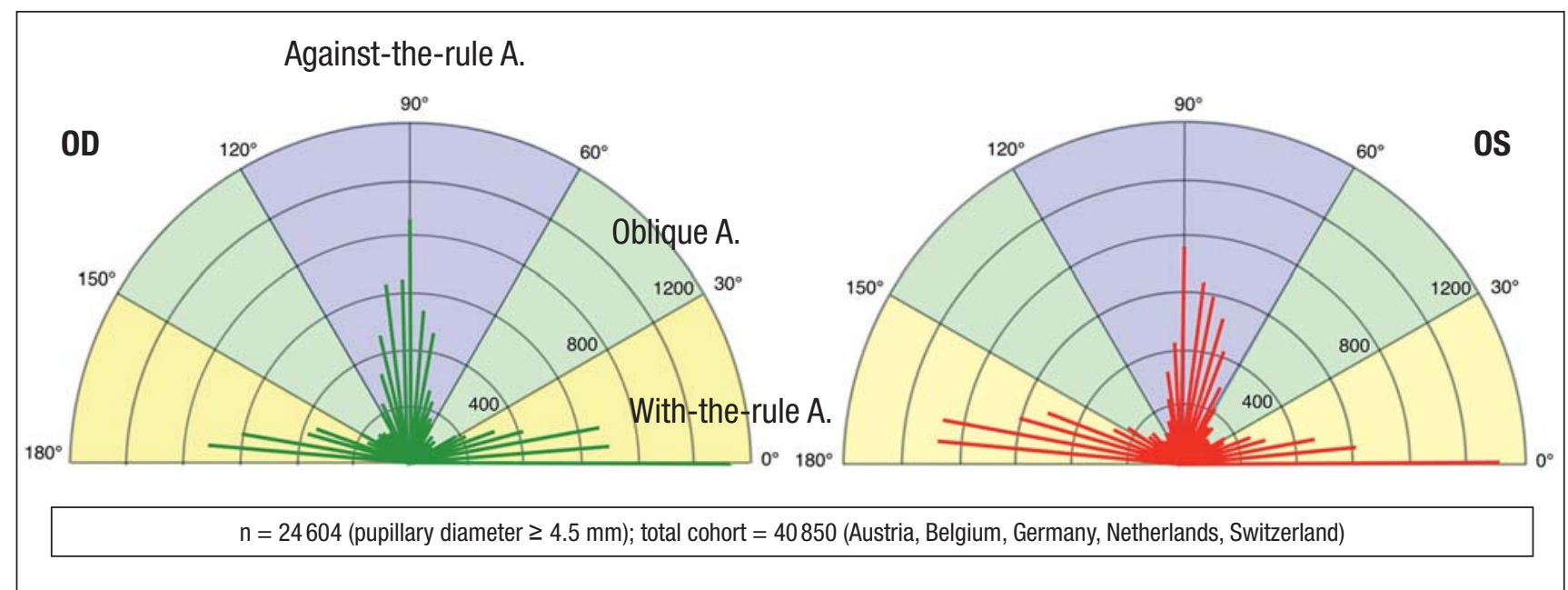

Figure 3: The frequency distribution of axis alignment of the corrective minus cylinder in a large population. The relative frequency of a given alignment of the axis is shown by the length of the radial lines and by the radii of the concentric arcs (from the smallest radius, corresponding to $n=200$, to the largest, corresponding to $\mathrm{n}=1200)$.

A., Astigmatism; OD, right eye; OS, left eye

fibers and the ciliary muscle $(30,31)$. Presbyopia usually begins in the middle of the fifth decade of life. A person with presbyopia can still see distant objects clearly but cannot focus on closer objects due to loss of accommodation capacity. The typical cardinal symptom is "short arms", when the patients find that he/she cannot hold a book or newspaper far enough from the eyes to read clearly.

The best-known option for correction of presbyopia is prescription of reading glasses (with plus effect) (18, 32). Refractive compensation for near and distant vision can be achieved with two separate pairs of glasses for far and near; with bifocal glasses (with two different refractive powers: far and near); occasionally with trifocal glasses (with three refractive powers/ zones: far, intermediate, and near); or with varifocal glasses (featuring progressive alteration of refractive power from far to near). Recently contact lenses and intraocular lenses with various refractive power zones have been introduced; however, it seems these lenses may show reduced image quality at relatively large pupillary diameters at dawn, twilight, or during the night (33-35). Correction by means of so-called monovision (one eye corrected for distance, the other for near vision) is also possible, but at the cost of restricted stereopsis (36).

\section{Deformation of the cornea}

The cause of cylindrical ametropia is usually deformation of the cornea. The much less common deformation of the ocular lens is harder to quantify.

\section{Anisometropia}

A refractive error is designated anisometropia when the two eyes differ in refractive power. The prevalence of an interocular discrepancy of $3 \mathrm{dpt}$ or more has been stated as 2 to $3 \%$ (37). Pronounced anisometropia may be accompanied by a pronounced difference in perception of image size (aniseikonia).

The term amblyopia characterizes weak sight/reduced visual acuity with no morphological correlate, as a result of impaired development of visual capacity. According to a large prospective cohort study, the prevalence of amblyopia in Germany is 5.6\% (38). Around $50 \%$ of cases of amblyopia are caused by anisometropia , $25 \%$ by squinting, and ca. $17 \%$ by a combination of the two (39). Children with high-grade anisometropia have a higher prevalence and greater severity of amblyopia than those with only a small difference in refractive power between the two eyes (39). Early screening of preschool children, though recommended, cannot alone detect all causes of amblyopia (40).

\section{Conclusion}

Simple functional tests that can be carried out in the office or outpatient department enable physicians with no special expertise in ophthalmology to differentiate 
swiftly and with adequate reliability between (primarily harmless) ametropia and other more serious causes of visual function disorders.

\section{Acknowledgments}

We are grateful to Elli Goldhorn for producing the photographs in eFigure 3, Maja Grigoleit for creating the graphics in eFigure 4, Matthias Müller for the visualization of frequency distributions in Figure 3 , and Thomas Kübler for the optical diagrams in eFigure 2. We also thank Dr. Ronald D. Gerste, Prof. Anne Buser, and all reviewers for their valuable advice.

\section{Conflict of interest statement}

Prof. Schiefer has received honoraria for consultancy from Servier, PharmAllergan, and Haag-Streit and payments for lectures from Alcon Pharma, Pharm-Allergan, MSD-Chibret, Pfizer, and Oculus.

The remaining authors declare that no conflict of interest exists.

Manuscript submitted on 26 February 2016, revised version accepted on 19 July 2016

\section{REFERENCES}

1. Taylor JF: Vision and driving. Practitioner 1982; 226: 68

2. Huang J, Wen D, Wang Q, et al.: Efficacy comparison of 16 interventions for myopia control in children: a network meta-analysis. Ophthalmology 2016; 123: 697-708.

3. Zentralverband der Augenoptiker und Optometristen: Brillenstudie 2014 | ZVA. www.zva.de/brillenstudie (last accessed on 24 September 2016).

4. Zentralverband der Augenoptiker und Optometristen: Branchenkennzahlen Augenoptik. www.zva.de/branchenkennzahlen (last accessed on 24 September 2016).

5. Wolfram C, Pfeiffer N: Weißbuch zur Situation der ophthalmologischen Versorgung in Deutschland. Deutsche Ophthalmologische Gesellschaft 2012

6. Zrenner E, Wilhelm H, Schiefer U: Differentialdiagnostische Strategien bei unklaren Sehstörungen. Ophthalmologe 1993; 90: 104-19.

7. Wesemann W, Schiefer U, Bach M: Neue DIN-Normen zur Sehschärfebestimmung. Ophthalmologe 2010; 107: 821-6.

8. Ophthalmische Instrumente - Sehzeichenprojektoren (DIN EN ISO 10938). Berlin: Beuth 1998. www.beuth.de/de/norm/ din-en-iso-10938/3725889 (last accessed on 24 September 2016).

9. Bach M: Freiburg Vision Test. www.michaelbach.de/fract/index.htm (last accessed on 24 September 2016).

10. Bach M: Optical illusions \& visual phenomena. http://michaelbach.de/data/DIN-Visus-2010/WSB-Visustafeln.pdf (last accessed on 24 September 2016)

11. Radner W: Ophthalmologische Leseproben Teil 1: Historische Aspekte. Ophthalmologe 2015 [Epub, ahead of print]

12. Radner W: Ophthalmologische Leseproben Teil 2: Aktuelle, logarithmisch abgestufte Leseproben. Ophthalmologe 2015 [Epub, ahead of print].
13. Diepes H: Refraktionsbestimmung. $3^{\text {rd }}$ edition. Heidelberg: DOZVerlag 2004.

14. Lachenmayr B, Hartmann E, Buser A: Auge - Brille - Refraktion: Schober-Kurs: verstehen - lernen - anwenden. $4^{\text {th }}$ edition. Stuttgart: Thieme 2005.

15. Methling D: Bestimmen von Sehhilfen. $3^{\text {rd }}$ edition. Stuttgart: Thieme 2012.

16. Friedburg D, Krause K: Subjektive Refraktionsbestimmung - Teil I: Optische Grundlagen. Ophthalmologe 2002; 99: 586-93.

17. Friedburg D, Krause K: Subjektive Refraktionsbestimmung - Teil II: Monokularer Feinabgleich. Ophthalmologe 2002; 99: 657-67.

18. Friedburg D, Krause K: Subjektive Refraktionsbestimmung - Teil III: Binokularabgleich, Nahbrille. Ophthalmologe 2002; 99: 734-41.

19. Lachenmayr B: Fallstricke bei der Bestimmung von Fernbrillen. Ophthalmologe 2011; 108: 318-23.

20. Grein HJ, Schmidt 0, Ritsche A: Zur Reproduzierbarkeit von Refrak tionsbestimmungen. Ophthalmologe 2014; 11: 1057-64.

21. Wolfram C, Höhn R, Kottler U, et al.: Prevalence of refractive errors in the European adult population: the Gutenberg Health Study (GHS). Br J Ophthalmol 2014; 98: 857-61.

22. Lee GA, Khaw PT, Ficker LA, Shah P: The corneal thickness and in traocular pressure story: where are we now? Clin Exp Ophthalmol 2002; 30: 334-7.

23. Bashford KP, Shafranov G, Tauber S, Shields MB: Considerations of glaucoma in patients undergoing corneal refractive surgery. Surv Ophthalmol 2005; 50: 245-51.

24. Shrivastava A, Madu A, Schultz J: Refractive surgery and the glaucoma patient. Curr Opin Ophthalmol 2011; 22: 215-21.

25. Lee JK, Chuck RS, Park CY: Femtosecond laser refractive surgery: small-incision lenticule extraction vs. femtosecond laser-assisted LASIK. Curr Opin Ophthalmol 2015; 26: 260-4.

26. Reinstein DZ, Archer TJ, Gobbe M: Small incision lenticule extraction (SMILE) history, fundamentals of a new refractive surgery technique and clinical outcomes. Eye Vis Lond Engl 2014; 1: 3.

27. Chou YS, Tai MC, Chen PL, Lu DW, Chien KH: Impact of cylinder axis on the treatment for astigmatic amblyopia. Am J Ophthalmol 2014; 157: 908-14. e1.

28. Abrahamsson M, Sjöstrand J: Astigmatic axis and amblyopia in childhood. Acta Ophthalmol Scand 2003; 81: 33-7.

29. Hartwig A, Atchison DA: Analysis of higher-order aberrations in a large clinical population. Invest Ophthalmol Vis Sci 2012; 53 : 7862-70.

30. Bron AJ, Vrensen GF, Koretz J, Maraini G, Harding JJ: The ageing lens. Ophthalmologica. 2000; 214: 86-104.

31. Gilmartin B: The aetiology of presbyopia: a summary of the role of lenticular and extralenticular structures. Ophthalmic Physiol Opt J Br Coll Ophthalmic Opt Optom 1995; 15: 431-7.

32. Krause H-K: Fallstricke bei der Bestimmung von Nahbrillen. Ophthalmologe 2011; 108: 324-30.

33. García-Lázaro S, Ferrer-Blasco T, Madrid-Costa D, Albarrán-Diego C, Montés-Micó R: Visual performance of four simultaneous-image multifocal contact lenses under dim and glare conditions. Eye Contact Lens 2015; 41: 19-24.

34. Woods J, Woods C, Fonn D: Visual performance of a multifocal contact lens versus monovision in established presbyopes. Optom Vis Sci 2015; 92: 175-82.

\section{Compensation by cylinder lenses}

Astigmatism leads to distortion of image perception and is compensated by means of cylinder lenses (exerting a non-rotational symmetry effect).

\section{Presbyopia}

A person with presbyopia can still see distant objects clearly but cannot focus on closer objects due to loss of accommodation capacity. 
35. Chen T, Yu F, Lin $\mathrm{H}$, et al.: Objective and subjective visual quality after implantation of all optic zone diffractive multifocal intraocular lenses: a prospective, case-control observational study. Br J Ophthalmol 2016: 22

36. Jain S, Arora I, Azar DT: Success of monovision in presbyopes: review of the literature and potential applications to refractive surgery. Surv Ophthalmol 1996; 40: 491-9.

37. Elflein HM, Pitz S: Amblyopie. Monatsschr Kinderheilkd 2015; 163 223-9.

38. Elflein HM: Amblyopie: Epidemiologie, Ursachen, Risikofaktoren. Ophthalmologe 2016; 113: 283-8.

39. Leon A, Donahue SP, Morrison DG, Estes RL, Li C: The age-depend ent effect of anisometropia magnitude on anisometropic amblyopia severity. J AAPOS 2008; 2:150-6.

40. Ehrt 0: Möglichkeiten und Grenzen des Amblyopiescreenings mit Autorefraktometern. Ophthalmologe 2016; 113: 289-95.

\section{Corresponding author}

Prof. Dr. med. Ulrich Schiefer

Kompetenzbereich "Vision Research"

Studiengang Augenoptik

Hochschule Aalen

Anton-Huber-Str. 23

73430 Aalen, Germany

ulrich.schiefer@hs-aalen.de

Supplementary material

For eReferences please refer to:

www.aerzteblatt-international.de/ref4116

eSupplement, eFigures:

www.aerzteblatt-international.de/16m0693

\section{FURTHER INFORMATION ON GME}

This article has been certified by the North Rhine Academy for Postgraduate and Continuing Medical Education. Deutsches Ärzteblatt provides certified continuing medical education (CME) in accordance with the requirements of the Medical Associations of the German federal states (Länder). CME points of the Medical Associations can be acquired only through the Internet, not by mail or fax, by the use of the German version of the CME questionnaire. See the following website: cme.aerzteblatt.de

Participants in the CME program can manage their CME points with their 15-digit "uniform CME number" (einheitliche Fortbildungsnummer, EFN). The EFN must be entered in the appropriate field in the cme.aerzteblatt.de website under "meine Daten" ("my data"), or upon registration. The EFN appears on each participant's CME certificate. This CME unit can be accessed until 8 January 2017, and earlier CME units until the dates indicated:

- "The Pharmacological Therapy of Chronic Neuropathic Pain" (issue 37/2016) until 11 December 2016,

- "The Diagnosis, Differential Diagnosis, and Treatment of Sarcoidosis" (Issue 33-34/2016) until 13 November 2016. 
Question 1

What is the proportion of German citizens over 16 who wear visual aids?
a) Circa $10 \%$
b) Circa $30 \%$
c) Circa $50 \%$
d) Circa $70 \%$
e) Circa $90 \%$

\section{Question 2}

What proportion of patients consult ophthalmologists because of problems with refractive issues?
a) Circa $3 \%$
b) Circa $13 \%$
c) Circa $21 \%$
d) Circa $53 \%$
e) Circa $70 \%$

\section{Question 3}

What enables relatively swift and simple identification of visual defects due to refractive errors?
a) Holding a pinhole aperture (stenopeic slit) in front of the eye
b) Direct ophthalmoscopy
c) The swinging flashlight test
d) Holding strong plus or minus lenses in front of the eye
e) Visual field examination (perimetry)

\section{Question 4}

What is directly quantified by visual acuity (vision)?
a) Contrast sensitivity
b) Sensitivity to glare
c) Sensitivity to differences in light density
d) Spatial resolution ability
e) Spatial perception

\section{Question 5}

Which kind of optotype is recognized internationally for certification of eyesight?
a) Rows of numerals
b) Rows of mixed letters and numerals
c) Blocks of text
d) The optotype chart
e) The 8-Position Landolt

\section{Question 6}

At what distance, in good light, can a person with visual acuity of 1.0 correctly identify around $60 \%$ of the round letters or numerals of a German automobile license plate?
a) Circa $15 \mathrm{~m}$
b) Circa $30 \mathrm{~m}$
c) Circa $45 \mathrm{~m}$
d) Circa $60 \mathrm{~m}$
e) Circa $100 \mathrm{~m}$

\section{Question 7}

What is the near vision of a person who can read normal newspaper type without hesitation at a distance of $\mathbf{4 0} \mathrm{cm}$ ?
a) Circa 0.1
b) Circa 0.2
c) Circa 0.5
d) Circa 0.8
e) Circa 1.0

\section{Question 8}

What characterizes anisometropia?

a) The relevant discrepancy in refractive power between the two eyes

b) The impaired ability of the eye to focus on close objects

c) Optical correction by plus glasses

d) Irregularity of the corneal surface

e) The deficient refractive power of the image-forming system in relation to eye length

Question 9

Approximately how many diopters are needed to correct a 1-mm deviation in the length of the eye?
a) $1 \mathrm{dpt}$
b) $3 \mathrm{dpt}$
c) $5 \mathrm{dpt}$
d) $7 \mathrm{dpt}$
e) $9 \mathrm{dpt}$

Question 10

In what circumstances does cylindrical ametropia arise?

a) When the radius of curvature is reduced

b) When oblique astigmatism is coupled with amblyopia

c) In rotational-symmetry distortion of visual objects

d) In the presence of asthenopic symptoms

e) In non-rotationally symmetrical deformation of the refractive media 


\section{Supplementary material to:}

\section{Refractive errors}

\section{Epidemiology, Effects and Treatment Options}

by Ulrich Schiefer, Christina Kraus, Peter Baumbach, Judith Ungewiß, and Ralf Michels

Dtsch Arztebl Int 2016; 113: 693-702. D0l: 10.3238/arztebl.2016.0693

$\Lambda$ ccording to DIN 58220 (7) and ISO 10938 (8) the so-called Landolt $\mathrm{C}$, with a gap at one of eight equally spaced positions, is the only optotype internationally accepted for certification of eyesight (Figure 1, eFigure 1). At least $60 \%$ of a line of at least five identically sized Landolt Cs with gaps in different positions must be read correctly for the corresponding level of vision to be assigned.

Lenses with a negative dioptric effect (minus lenses) have a miniaturizing effect that is noticed both by the wearers and by those looking at them. An eye behind a minus lens appears smaller - most prominently, the temporal margin of the orbit seems to be shifted medially (eFigure $3 b$ ). eFigure $3 a-c$ gives an impression of the extent of orbital margin distortion depending on the refractive power of the corrective glasses.

The eye of a person wearing hyperopic glasses appears larger - the temporal margin of the orbit seems to be displaced laterally (eFigure 3c). Again, the extent of the distortion depends on the power of the lenses.

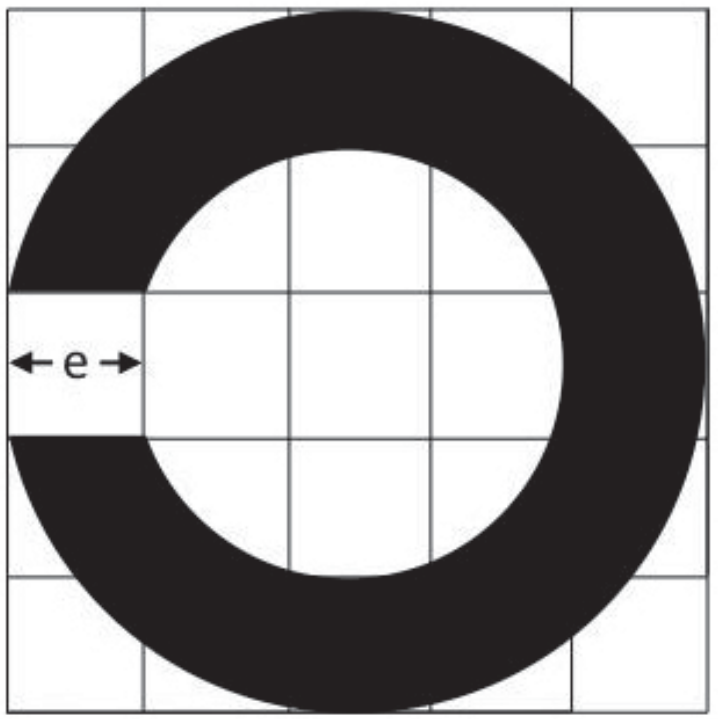

eFigure 1: Landolt C: The optotype is contained in a square made up of $5 \times 5$ smaller squares of edge length $e$. The line width of the $C$ and the breadth of the gap correspond to e. The gap can be situated in any of eight evenly spaced positions. The visual angle under which the gap is discernable specifies the visual acuity of the eye.

\section{Classification of astigmatism by axis alignment \\ With-the-rule astigmatism}

In with-the-rule astigmatism, the most common form of this visual defect, the axis of the corrective minus cylinder is almost horizontal $\left(0^{\circ}-30^{\circ}\right.$ or $150^{\circ}$ - $180^{\circ}$; eFigure $5 b$ and Figure 3); objects are vertically distorted/straightened. One of the causes is the tension of the horizontally aligned upper and lower lid edges (like a ball compressed from above and below; see Figure 2). Uncorrected, the increased perpendicular refractive power leads to distortion/ elongation of image perception in the vertical plane. Some patients find that this vertical enlargement of letters, comparable to the effect of a magnifying ruler, actually makes reading easier, compared with the original situation (eFigure $5 a$ ).

\section{Against-the-rule astigmatism}

In against-the-rule astigmatism, the second most frequently occurring type, the axis of the corrective minus cylinder is almost vertical $\left(60^{\circ}-120^{\circ}\right.$; eFigure $5 c$ ) and objects are distorted in the horizontal direction.

\section{Oblique astigmatism}

In oblique astigmatism the axis of the corrective minus cylinder is slanted at either $30-60^{\circ}$ or 120-150 (eFigure $5 d$ ), so objects are distorted diagonally. This form of astigmatism-especially in severe monocular/unilateral cases - is associated with a high risk of amblyopia. In this constellation there is a discrepancy between the (distorted, tilted) visual perception and the actual (horizontal or vertical) alignment as conveyed by proprioception or touch. The simplest way of eliminating such "confusion" is to functionally/ neuronally "switch off" the affected eye. The result is amblyopia-a reduction in function without a (macroscopically and structurally) explicable correlate. The affected person has reduced visual acuity, particularly for characters placed closely together, which cannot be adequately separated from one another (crowding). This problem particularly affects reading ability $(27$, 28). 


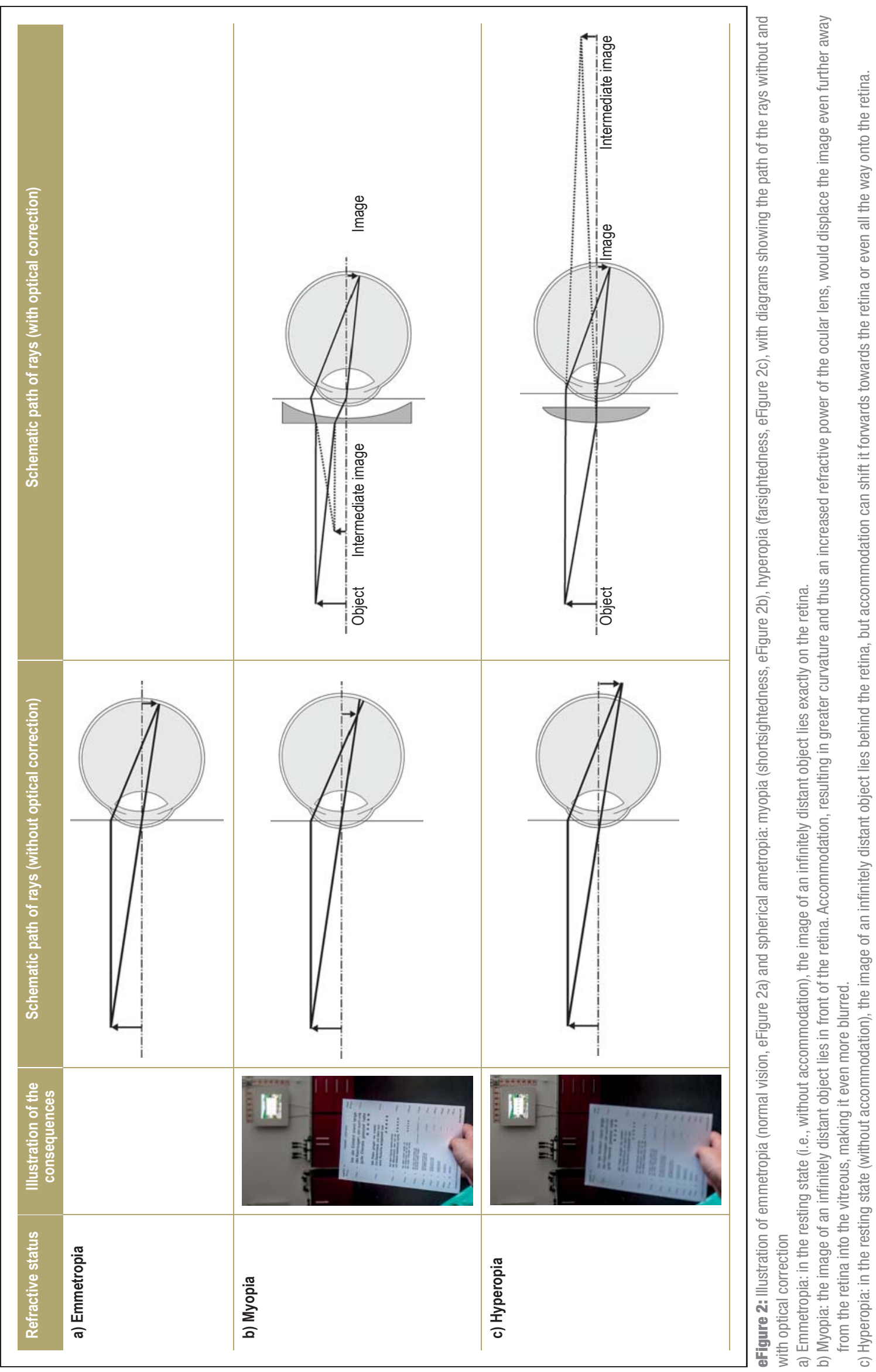


a

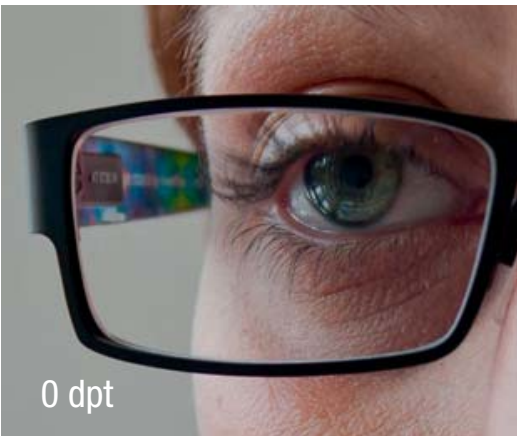

b
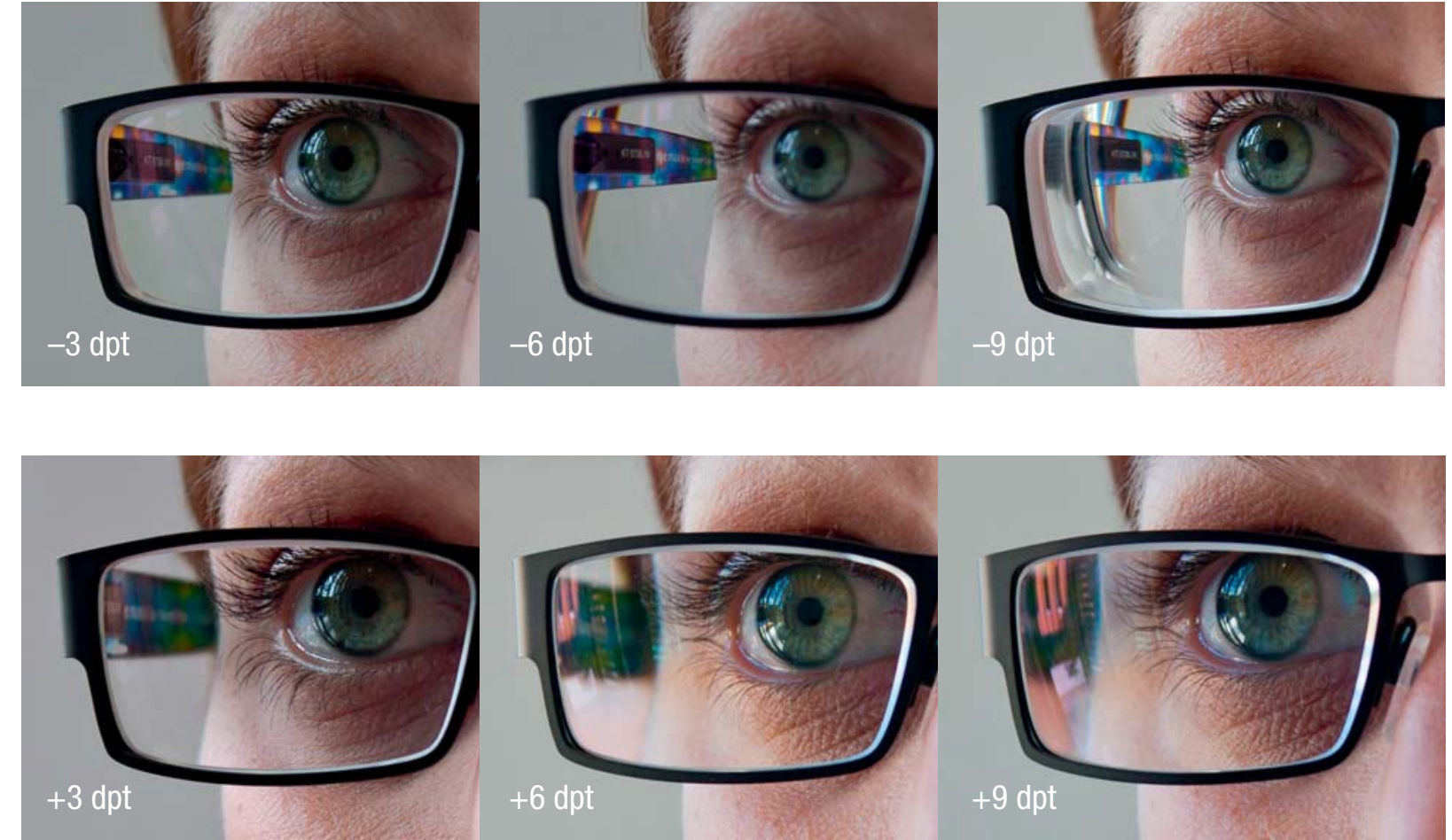

eFigure 3: Distortion of the temporal margin of the orbit by minus and plus lenses of varying refractive power a) Emmetropia (0 dpt)

b) Myopia (-3,0 dpt, $-6,0 \mathrm{dpt},-9,0 \mathrm{dpt})$

c) Hyperopia (+3,0 dpt, +6,0, +9,0 dpt) 


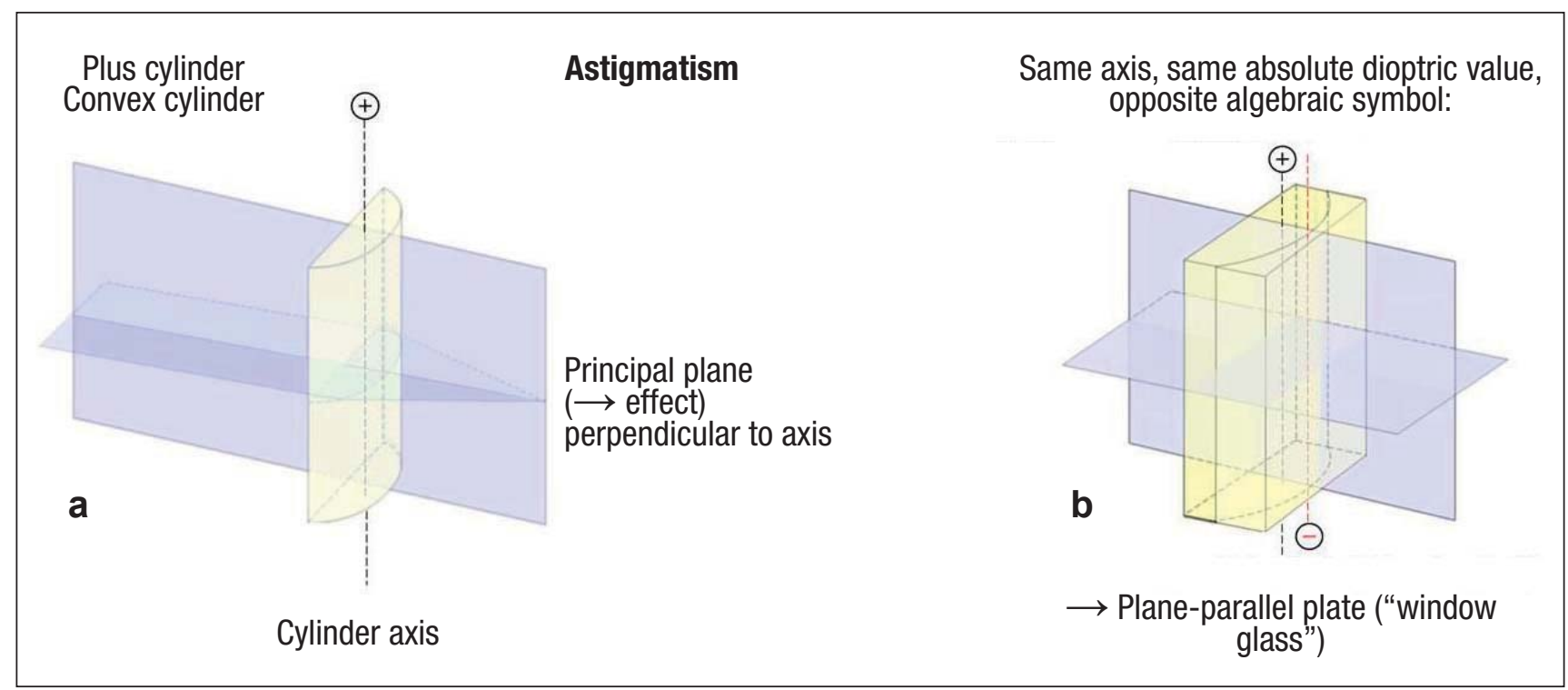

eFigure 4: Cylindrical ametropia and its optical correction

a) How a (plus) cylinder lens functions: This is a segment of a glass cylinder. The principle plane parallel with the axis of the cylinder has no optical effect, but the principle plane perpendicular to the axis of the cylinder exerts the maximum optical effect.

b) Compensation of cylindrical ametropia by addition of a corrective cylindrical lens that has an identical alignment of the axis and the absolute dioptric value but opposite algebraic symbol (plus instead of minus, or vice versa).. This results in an optically neutral (i.e., optically ineffective) "plane-parallel plate". 

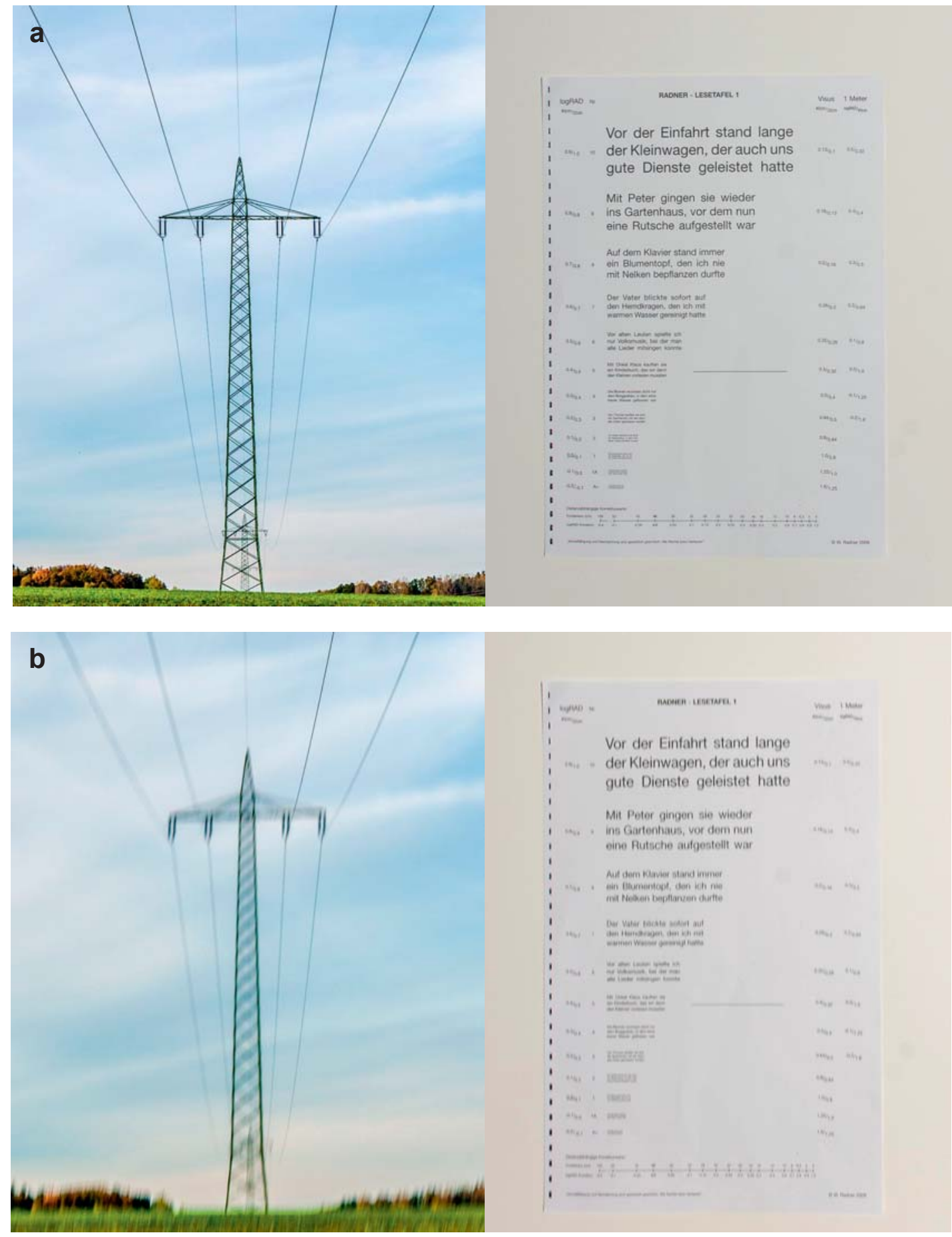

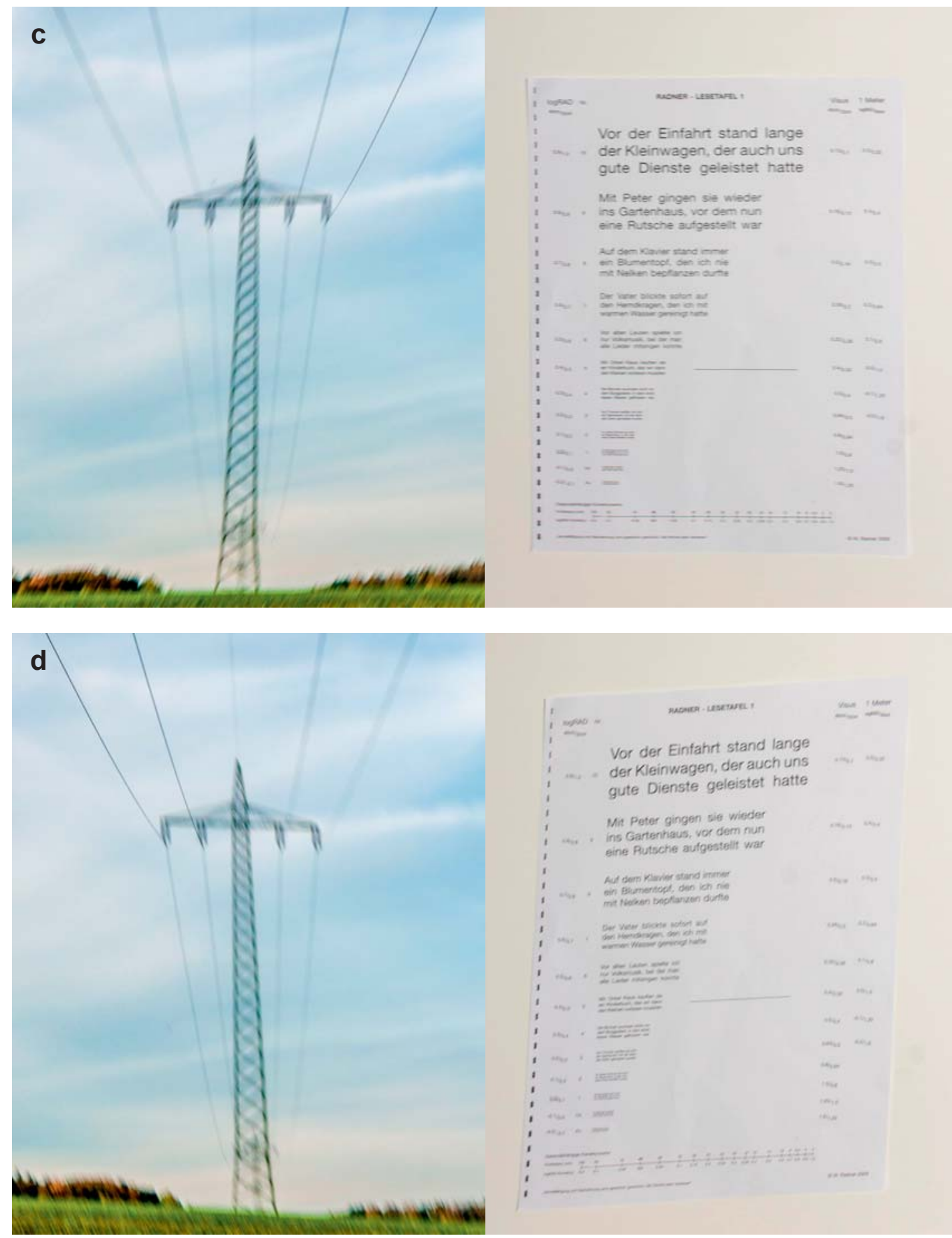

eFigure 5a-d: Classification and effect of astigmatism depending on the axis alignment of the corrective minus cylinder (or of the more anterior focal line) - illustrated using a standardized reading text (Radner chart). The photographs are intended to depict the visual impression; this always depends on which of the focal lines lies closer to the retina.

a) Original situation (left: distant vision, right: Radner near reading test);

b) With-the-rule astigmatism: the more anterior focal line is almost horizontal; this is then also true for the axis of the corrective minus cylinder: $0^{\circ}-30^{\circ}$ or $150^{\circ}-180^{\circ}$ (Figure 3).

c) Against-the-rule astigmatism: the more anterior focal line is almost vertical; this is then also true for the axis of the corrective minus cylinder: $60^{\circ}-120^{\circ}$ (Figure 3 ).

d) Oblique astigmatism: the axis of the corrective minus cylinder is oblique: $30^{\circ}-60^{\circ}$ or $120^{\circ}-150^{\circ}$. 